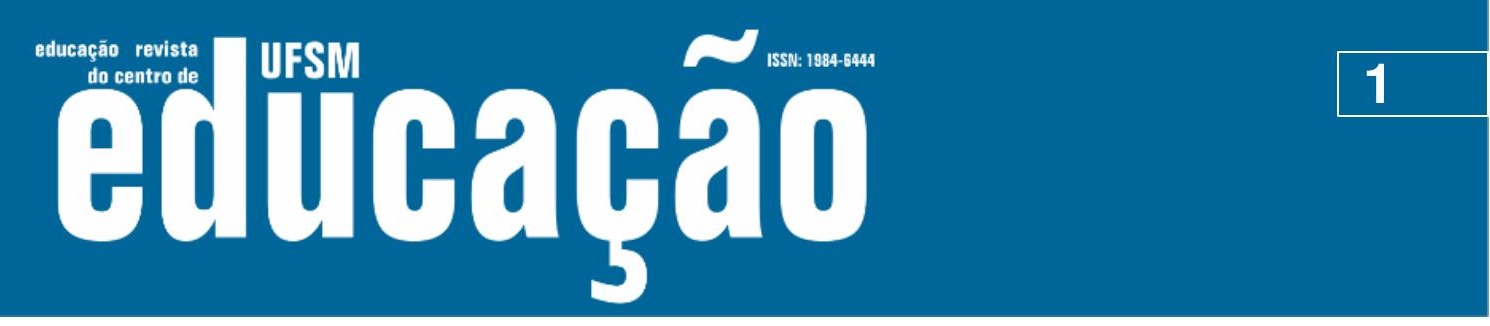

ISSN: 1984-6444 | http://dx.doi.org/10.5902/1984644433097

\title{
O Programa Tutoria Educacional para a formação continuada de professores
}

\author{
The Educational Tutorial Program for the continuing education of \\ teachers
}

* Rudervania da Silva Lima Aranha

Doutoranda na Universidade Federal do Amazonas, Manaus, Amazonas, Brasil.

rudervania.aranha@gmail.com - http://orcid.org/0000-0002-7111-0720

\section{** Selma Suely Baçal de Oliveira}

Professora associada da Universidade Federal do Amazonas, Manaus, Amazonas, Brasil. selmabacal@ufam.edu.br- http://orcid.org/0000-0001-6765-4568

Recebido em 14 de junho de 2018

Aprovado em 20 de maio de 2019

Publicado em 15 de julho de 2019

\section{RESUMO}

Este artigo discute a materialização do Programa Tutoria Educacional (PTE) para formação continuada de professores da educação básica no munícipio de Manaus (AM). Trata-se da síntese de resultados de pesquisa empírica. Problematizando a implementação do Projeto de Expansão e Melhoria Educacional da Rede Pública de Manaus (PROEMEM) na rede pública municipal de ensino de Manaus, evidenciando a lógica do mercado educacional. Esses movimentos explicam as conjunturas marcadas pelos organismos internacionais no processo de globalização da reforma educacional, desempenhando o papel ideológico de propagadores dos ideais neoliberais. Tem como objetivo analisar a materialidade das políticas neoliberais estabelecidas pela implantação do PROEMEM na Secretaria Municipal de Educação. O estudo, de caráter crítico, apresenta por meio de análise teórica e documental discussão acerca dos princípios que permitem eleger a parceria com o setor privado nas etapas da educação básica do ensino público municipal em Manaus, com a análise centrada nas categorias do público e do privado na educação.

Palavras-chave: Programa de Tutoria Educacional; Público e Privado; Formação Continuada de Professores. 


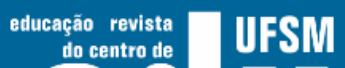 Eutuab̧a}

ISSN: 1984-6444 | http://dx.doi.org/10.5902/1984644433097

Educação Municipal, deu-se início a elaboração do PROEMEM com o intuito de solicitar empréstimo ao BID, cuja exposição de resultados foi por meio do primeiro workshop, tendo como objetivo apresentar um diagnóstico das fragilidades da educação pública municipal naquele período.

Para desenvolver este estudo, foi realizada revisão de literatura, levantamento e análise de documentos primários, entre eles, estão documentos oficiais da SEMED e Relatórios Anuais, que estão no endereço eletrônico do Banco Interamericano de Desenvolvimento, bem como os documentos relativos à concretização do PROEMEM e ações efetivadas pelo referido projeto no período de 2013 a 2017. Desvelando assim, o convênio firmado entre a SEMED com a Fundação Itaú Social, por meio do Programa Tutoria Educacional, que vem se configurando como um modelo verticalizado e promove mudanças nas concepções de escola pública.

Esses movimentos explicam as conjunturas marcadas pelos organismos internacionais no processo de globalização da reforma educacional, desempenhando o papel ideológico de propagadores dos ideais neoliberais. A aceitação dessa lógica promove mudanças nas concepções de escola pública, com a incorporação de instituições privadas na rede municipal de ensino, com uma nova justificação éticomoral e política privatizante e mercantil no projeto de Educação. Esse processo viabiliza a expansão de instituições privadas no setor educacional que encontram novos nichos de exploração econômica, e permitem a apropriação privada do bem público, sem, contudo gerar efetivamente a melhoria da rede escolar pública.

\section{PROEMEM: primeiras aproximações}

A partir do ano de 2013, período marcado pela articulação dos assessores do Banco Interamericano de Desenvolvimento (BID) com a gestão da Educação Municipal, deu-se início a elaboração do Projeto de Expansão e Melhoria Educacional da Rede Pública Municipal de Manaus (PROEMEM), com o intuito de solicitar empréstimo ao BID. A partir de então, foi feito um levantamento de dados em todos os departamentos da SEMED, para elaboração do referido projeto. No ano de 2014, com a publicação no Diário Oficial do Município (DOM), foi aprovada a Lei municipal 


\section{工 WFM entuarga}

ISSN: 1984-6444 | http://dx.doi.org/10.5902/1984644433097

no 1.921 , de 30 de Outubro de 2014, essa Lei municipal foi revogada pela Lei municipal nº 2.230, de 04 de julho de 2017, que reestrutura o PROEMEM para ser executado pelo período de 2017 a 2021, no âmbito da SEMED. Durante a análise do referido projeto, arquitetado com o objetivo anunciado de expandir a cobertura e melhorar a qualidade da educação infantil e do ensino fundamental, ficou evidente a necessidade de pesquisar além do que estava proposto no projeto, visto que as indicações pelo PROEMEM apresentam em uma de suas ações a implantação dos Programas de Correção de Fluxo. Por indicação do BID, a Secretaria Municipal de Educação, por meio do PROEMEM, iniciou no ano de 2014 o diálogo com o Instituto Ayrton Senna (IAS) - uma instituição sem fins lucrativos que presta assessoria a estados e municípios em assuntos concernentes à Educação - principalmente no tratamento de Programas de Correção de Fluxo. Ainda neste mesmo ano, a SEMED contratou o Instituto Áquila para a implementação do Sistema Integrado de Gestão da Educação (GIDE). Este sistema visa a introduzir uma série de indicadores estratégicos de gestão escolar, formando uma equipe de 100 coordenadores pedagógicos responsáveis pela melhoria da gestão escolar e pelo apoio às escolas em suas ações de melhoria para auxiliar na implementação do Sistema Integrado de Gestão da Educação (GIDE), instituição também indicada pelo BID.

Ainda de acordo com o documento do PROEMEM, foram firmadas duas negociações com o setor privado: uma, com Instituto Ayrton Senna (IAS), para o atendimento aos alunos em distorção idade-série, principalmente aqueles matriculados no $3^{\circ}, 4^{\circ}$ e $5^{\circ}$ anos do Ensino Fundamental; e outra, com a Fundação Itaú Social (FIS), sendo implantado o Programa de Tutoria Educacional (PTE) que é uma metodologia de formação continuada em serviço que se apoia na observação da prática, em ações modelares realizadas pelo tutor, em seções customizadas de planejamento das ações realizadas (MANAUS, 2015), para atendimento aos professores em estágio probatório iniciantes na atividade profissional na Rede Municipal de Educação no período de três anos, como determina o Art. 41 da CF/88, com redação dada pela Emenda Constitucional nำ 19/06/1998 e pela Lei Municipal no 1.128, de 05 de junho de 2007, que dispõe sobre o Plano de Cargos, Carreiras e 


\section{口 entoarga}

ISSN: 1984-6444 | http://dx.doi.org/10.5902/1984644433097

Subsídios dos Professores do Magistério do Município de Manaus. Esses movimentos explicitam as conjunturas marcadas pela globalização econômica e pelos organismos internacionais, consubstanciando-se na reforma educacional que se desencadeia desde o século XX e intensificando-se, a partir da década de 1990, com desdobramentos que, nos dias atuais, continuam desempenhando papel ideológico de propagadores do sistema capitalista, com princípio neoliberal.

A pesquisa que permitiu a apropriação do objeto de estudo foi realizada com fontes primárias, basicamente documentos e sites das instituições envolvidas (SEMED, BID e FIS), que muito contribuíram para ampliar a compreensão e a reflexão sobre os processos da tal parceria com o setor privado na educação pública no município de Manaus. Assim, é importante enfatizar a contextualização crítica das políticas educacionais e das ações resultantes de projetos de parcerias, contratos ou convênios entre setores públicos e privados que se consolidam a partir dos resultados de pesquisa, estudos e análises sobre as propostas de reforma do Estado, produzidas em âmbito internacional e nacional.

Portanto, a proposta metodológica do Programa de Tutoria Educacional, apresentada pela Fundação Itaú Social, surge como aparente solução para a definição de estratégias educacionais para o enfrentamento das questões relativas à educação infantil e ao ensino fundamental na rede pública municipal de ensino. A Fundação Itaú Social declara ter como proposta de atuação: "formular, implantar e disseminar metodologias voltadas à melhoria de políticas públicas na área educacional e à avaliação de projetos sociais" (FUNDAÇÃO ITAÚ, 2013, p. 9). Nessa perspectiva, "essa questão constitui um desafio significativo para a consecução do projeto hegemônico de reestruturação do capital, sob comando neoliberal" (MONTAÑO, 2014, p. 23).

Esse processo de parceria com o setor privado (lucrativo ou não lucrativo) tem dado materialidade a uma nova lógica do mercado na organização educacional, que tende a ser fetichizado pelos produtos e pelos serviços negociados com a SEMED em Manaus. Nessa lógica, a política privatista consolidada pelos contratos e convênios vem acompanhada de um reforço da aparência a fim de diluir as distinções entre o 


\section{A wism entioará}

ISSN: 1984-6444 | http://dx.doi.org/10.5902/1984644433097

público e o privado, considerado como um "processo conflituoso e contraditório" (NORONHA, 2005, p. 145), implicando em duplo movimento - conservador e transformador - e constituindo a essência do modo de produção capitalista.

O PROEMEM estrutura-se em quatro componentes, descritos a seguir: Componente 1 (um) - Expansão e Melhoria da Cobertura da Educação Infantil e do Ensino Fundamental; Componente 2 (dois) - Melhoria da Qualidade da Educação; Componente 3 (três) - Gestão, Monitoramento e Avaliação; Componente 4 (quatro) Administração do Projeto. Esses componentes contam com recursos financeiros programados para execução total em cinco anos.

Destacam-se as ações provenientes do Componente 2 que "permite qualificar o profissional em estágio probatório e assegurar o desenvolvimento das competências e habilidades necessárias para o processo de ensino e aprendizagem do aluno" (MANAUS, 2015, p. 3), sendo essa a justificativa para o convênio entre a SEMED e a Fundação Itaú Social. Uma vez efetivado, o convênio tem inserido a lógica do mercado no sistema público municipal de ensino, evidenciando um projeto de sociedade no qual a política educacional está a serviço dos interesses do grande capital.

Os primeiros encaminhamentos para o estabelecimento da parceria entre a SEMED e a Fundação Itaú Social, no atendimento aos professores da educação infantil e dos anos iniciais do ensino fundamental em estágio probatório - professores iniciantes na atividade profissional na rede municipal de educação passarão por três anos em período probatório, como determina o Art. 41 da Constituição Federal de 1988, com redação dada pela Emenda Constitucional № 19/06/1998 e pela Lei municipal $\mathrm{n}^{0}$ 1.128, de 05 de junho de 2007, que dispõe sobre o Plano de Cargos, Carreiras e Subsídios dos Professores do Magistério do Município de Manaus, ocorreram no ano de 2014, com a participação de educadores do Departamento de Gestão Educacional (DEGE), chefes das Divisões Distritais Zonais (DDZs), além da subsecretaria de Gestão Educacional dessa Secretaria. Os representantes da SEMED-Manaus participaram da Formação em Serviço realizada em Manaus pela assessoria pedagógica da Fundação Itaú Social, para expor a metodologia do Programa Tutoria Educacional (PTE) dessa Fundação. 


\section{DFM efituaráo}

ISSN: 1984-6444 | http://dx.doi.org/10.5902/1984644433097

No início do ano de 2015, a Fundação Itaú Social encontrava-se em fase de negociação para o convênio com a SEMED, firmado somente em 30 de setembro do referido ano. Entretanto, em março de 2015, a Fundação Itaú Social, com apoio técnico do Centro Integrado de Estudos e Programa de Desenvolvimento Sustentável (CIEDS) - instituição social sem fins lucrativos, de utilidade pública federal, fundada em 1998, com sede na cidade do Rio de Janeiro e filiais em São Paulo e em Minas Gerais e que atua, desde a sua criação, em diversos municípios do Brasil, com diferentes parceiros institucionais, sendo essa instituição indicada pela Fundação Itaú Social para realizar a seleção de tutores do Programa Tutoria Educacional (PTE) em Manaus, realizou o primeiro processo seletivo interno para a vaga de tutor - termo utilizado para designar o profissional que realiza o acompanhamento ao professor no cotidiano da sala de aula, para atuarem nas escolas do município de Manaus, ficando - CIEDS o responsável pelo processo de seleção, formação e acompanhamento desses tutores, denominados de tutores regionais. Foi realizado também pelo CIEDS o segundo processo seletivo, tendo agora como público-alvo os tutores educacionais, selecionados para atuarem nas escolas municipais. Esses tutores educacionais realizaram estudos do material denominado "Guia de Tutoria" e, para a divulgação e - lançamento do Programa Tutoria na SEMED, com a realização de oficina de apresentação do referido Programa para assessores pedagógicos, diretores e professores das escolas dessa secretaria. Aos professores foi solicitado ao final da oficina a assinatura da adesão ao Programa Tutoria Educacional da Fundação Itaú Social.

Em agosto de 2015, teve início o acompanhamento dos Tutores Educacionais e Tutores Regionais nas unidades escolares e, finalmente, como já sinalizado, em 30 de setembro, foi assinado o Termo de Convênio no 12/2015 entre a SEMED e a Fundação Itaú Social com objetivo de definir estratégias e análises necessárias à implementação de soluções educacionais para o enfrentamento das questões relativas à Educação Infantil e ao Ensino Fundamental na Rede Municipal de Ensino, por meio do Programa Tutoria Educacional. 


\section{口 entuară}

ISSN: 1984-6444 | http://dx.doi.org/10.5902/1984644433097

É importante entender os pressupostos e as intenções envolvidos nessa modalidade de parceria com o setor privado em educação, que garantem a inserção da lógica do mercado para a educação pública municipal: "é o destaque atribuído à modalidade formativa baseada em práticas de acompanhamento que pressupõe a atuação de figuras como a do tutor" (SARTI, 2012, p. 326). Com esse imbricamento da relação entre a Fundação Itaú Social e a SEMED, para atender as demandas da educação pública na rede municipal de ensino, é possível verificar que as fronteiras entre o público e o privado se articulam e as divergências entre essas duas esferas permanecem contraditórias e antagônicas.

As contradições estão postas quando se considera o previsto pelo decreto de no 6.094, de 24 de abril de 2007, que dispõe sobre a implementação do Plano de Metas Compromisso de Todos pela Educação, em que os direcionamentos para o trabalho docente podem ser vistos em algumas de suas diretrizes. Notadamente, a gestão pública administrativa e pedagógica é influenciada pela iniciativa privada, como podemos perceber na SEMED, pois esta Secretaria conta com o Instituto Ayrton Senna para o atendimento aos seus alunos do ensino fundamental, de acordo com o documento intitulado "Implantação dos Programas de Correção de Fluxo em parceria com o Instituto Ayrton Senna", que anuncia os programas de correção de fluxo - Se Liga, para alunos não alfabetizados, e Acelera Brasil, para alunos alfabetizados atendendo "à lógica da segunda oportunidade, na medida em que visam ao desenvolvimento das competências necessárias a sua realização pessoal e profissional, oportunizando o pleno sucesso dos educandos" (MANAUS, 2016, p. 3).

Tudo isso, é possível perceber a ocorrência de fatores relacionados via desregulamentação da legislação na educação nacional e municipal. O enfraquecimento do Estado reduz sua capacidade de organização e de controle de bens e normatiza um quadro legal e institucional para garantir a elevação de empreendimentos de interesse do mercado no interior de escolas públicas.

Com essa perspectiva, considera-se que a parceria com o setor privado em educação oculta interesses hegemônicos do grande capital de forma disfarçada e camuflada para legitimar seus projetos e programas, como, por exemplo, o Programa 


\section{A Husm entuargá}

ISSN: 1984-6444 | http://dx.doi.org/10.5902/1984644433097

Tutoria Educacional (PTE). Percebe-se, desse modo, que a presença do privado no público apresenta uma crescente sofisticação dos discursos pedagógicos, delineando novos horizontes para o trabalho da docência e funcionando como uma atividade organizativa que, em Manaus, se efetiva no trabalho dos professores em estágio probatório da educação infantil (creche e pré-escola) e dos anos iniciais do ensino fundamental. Consolida-se e amplia-se, nesse contexto, um grande mercado que "vem sendo disputado por diferentes instituições" (SARTI, 2012, p.329). Nesse sentido, pesquisas relativas a essa questão são realizadas por Maués (2003; 2006; 2014), Sarti (2012; 2014) e Souza (2006; 2014), entre outros.

Considera-se esse objeto de análise como fator de contradições nessas relações, de equívocos nos discursos defendidos e de instrumentos ideológicos, tornando extremamente complexos os recursos empregados pelas classes dominantes para debilitar a luta de classes, pois "somente uma visão mais abrangente, considerando os aportes das mais variadas áreas das ciências do homem, poderá levar a uma compreensão maior do mundo atual" (VIDIGAL, 2011, p. 14). Assim, a atuação do Estado tem sido disputada com o setor privado, evidenciando a participação do empresariado, que se concretizou como agente político no decorrer do século XX, com o apoio de setores organizados da sociedade civil, de modo que os interesses mercantis vêm prevalecendo.

A aceitação de projetos de parcerias, contratos e convênios com o setor privado na educação pública faz parte de um processo mais amplo de "reestruturação da vida econômica, política, jurídica e cultural das sociedades capitalistas contemporâneas, sem deixar de reconhecer que a privatização constitui uma estratégia global da atual reestruturação capitalista" (GENTILI, 1998, p. 73). É precisamente dentro deste contexto que se deve compreender a parceria com o setor privado e todas as ações voltadas para a estimulação e disseminação da mesma, evidenciando-se uma nova investida do capital.

O processo desencadeador da política educacional municipal, no qual a parceria com o setor privado foi normatizada, permitindo assim, a institucionalização de interesses privados nas etapas da educação básica municipal, iniciou-se 


\section{HEM entinabá}

ISSN: 1984-6444 | http://dx.doi.org/10.5902/1984644433097

primeiramente com a implantação e execução do PROEMEM. Diante disso, cresce, consideravelmente, o envolvimento de fundações e institutos ligados a grupos financeiros que investem fortemente na educação, sob a lógica do mercado educacional. A implicação do setor empresarial nas questões sociais tem crescido substancialmente, sendo assunto que requer maior atenção, reflexão e análise por parte dos educadores e demais profissionais comprometidos com a educação brasileira.

O PROEMEM, em seu objetivo geral, anuncia que pretende ampliar a cobertura e melhorar a qualidade da educação infantil e ensino fundamental da rede municipal, partindo da premissa de inclusão para quatro ações componentes. Observe o quadro abaixo detalhando a distribuição dos custos financeiros para a execução das ações dos componentes do PROEMEM:

Quadro 1- Custos Financeiros do PROEMEM

\begin{tabular}{|c|c|c|}
\hline AÇÃO & OBJETIVOS & TOTAL \\
\hline $\begin{array}{l}\text { COMPONENTE } \\
\text { Expansão e Melhoria da } \\
\text { Cobertura da Educação } \\
\text { Infantil e } \quad \text { Ensino } \\
\text { Fundamental. }\end{array}$ & $\begin{array}{l}\text { Expandir o acesso à educação básica, } \\
\text { compreendendo a educação infantil e o ensino } \\
\text { fundamental, por intermédio da construção de } \\
\text { unidades de ensino de educação básica. }\end{array}$ & $\begin{array}{l}\text { U\$ } \\
63.380 .000,00\end{array}$ \\
\hline $\begin{array}{l}\text { COMPONENTE 2: } \\
\text { Melhoria da Qualidade } \\
\text { da Educação }\end{array}$ & $\begin{array}{l}\text { Aprimorar o rendimento e o desempenho escolar dos } \\
\text { alunos da rede pública municipal de ensino. }\end{array}$ & $\begin{array}{l}\text { U\$ } \\
26.260 .000,00\end{array}$ \\
\hline $\begin{array}{l}\text { COMPONENTE } \\
\text { Gestão, Monitoramento e } \\
\text { Avaliação }\end{array}$ & $\begin{array}{l}\text { Fortalecer a educação básica por meio de projetos } \\
\text { pedagógicos e reforço escolar, aceleração da } \\
\text { aprendizagem, seleção e formação de professores } \\
\text { formadores, gestão, monitoramento e avaliação do } \\
\text { desempenho escolar dos alunos da rede pública } \\
\text { municipal de ensino. }\end{array}$ & U\$ 8.030.000,00 \\
\hline $\begin{array}{l}\text { COMPONENTE } \\
\text { Administração do Projeto }\end{array}$ & $\begin{array}{l}\text { Robustecer a capacidade institucional da SEMED para } \\
\text { gerenciar, monitorar e avaliar o sistema educativo } \\
\text { municipal. }\end{array}$ & U\$ 6.330.000,00 \\
\hline TOTAL & & $\begin{array}{l}\text { U\$ } \\
104.000 .000,00\end{array}$ \\
\hline
\end{tabular}

Fonte: MANAUS, 2013. (Elaboração da autora). 


\section{WsM entoarga}

ISSN: 1984-6444 | http://dx.doi.org/10.5902/1984644433097

O quadro 1 mostra os desembolsos previstos para a execução das ações do PROEMEM para o período de 2017 a 2021. Os parâmetros de custos financeiros foram disponibilizados pelo BID. Nesse quadro, pode-se verificar esses fluxos em dólares correntes, calculados com base em uma taxa de câmbio de 3,09930. O custo total em valores correntes é de US\$104.000.000,00 (BRASIL, 2017). Como pode-se notar pelo referido quadro, os custos estão divididos em 4 componentes:

O Componente 1 - tem como ação expandir a cobertura e melhorar a educação infantil e ensino fundamental, constituem a maior parte dos custos do projeto, que corresponde a $\bigcup \$ 63.380 .000,00$, que anuncia como objetivo ampliar a cobertura da educação infantil e ensino fundamental e a expansão e melhoria da infraestrutura escolar. Este componente deve financiar: a construção de Centros de Educação Infantil (CMEI) e creches; construção de Escolas Municipais de Ensino Fundamental (EMEF) e aquisição de bens e materiais duráveis para equipar as unidades.

O Componente 2 - tem como ação melhorar a qualidade da educação. Compõe no total de despesas $U \$ 26.260 .000,00$. Este componente anuncia como objetivo melhorar o desempenho dos alunos da rede da educação infantil e ensino fundamental, e deve financiar: a implementação de programas de aceleração da aprendizagem e reforço escolar com o apoio do Instituto Ayrton Senna (IAS); reformulação de concursos para seleção de novos professores, bem como a revisão do período de estágio probatório, acompanhando professores contratados por meio de um sistema de coaching e também processo seletivo de formadores para atuarem na formação continuada da SEMED, responsáveis pela formação de professores e diretores da rede, com formação em nível de mestrado profissional e treinamento; projetos educacionais para a melhoria do desempenho educacional e gestão escolar, selecionados criteriosamente para a obtenção de um fundo de investimento; e o desenvolvimento de matrizes curriculares articuladas para facilitar as transições entre níveis de ensino.

O Componente 3 - tem como ação a gestão, monitoramento e avaliação. Compõem U\$ 8.030.000,00 no total de despesas previstas para esse componente. Este componente anuncia como objetivo reforçar a capacidade de gestão da rede de 


\section{THEM entinab̧a}

ISSN: 1984-6444 | http://dx.doi.org/10.5902/1984644433097

ensino da SEMED. Isso levaria as atividades relativas à: implementação de novos processos de seleção e avaliação de professores e administradores; implementação do Sistema de Avaliação de Desempenho Educacional de Manaus (SADEM), que terá três componentes: Avaliação de Desempenho Escolar (ADE), Sistema Estadual de Avaliação do Estado do Amazonas (SADEAM) e Avaliação Gestão Escolar (AGE).

E o Componente 4 - tem como ação a gestão do Projeto. Compõem no total de despesas previstas de U\$6.330.000,00. A fim de proporcionar a execução do Projeto, será realizada a criação da Unidade de Gerenciamento de Projetos (UGP); a aquisição de bens para o seu funcionamento e a prestação de apoio à gestão e auditoria externa.

\section{O MERCADO EDUCACIONAL PARA REDE PÚBLICA MUNICIPAL DE MANAUS}

Primeiramente, as asserções sobre o público e o privado constituem-se como categorias correlatas e indissociáveis. Entende-se que "se comportam como polos opostos que se supõem um ao outro. Portanto, o público só pode ser compreendido por referência ao privado e vice-versa" (SAVIANI, 2005, p. 168). Ou seja, quando se estuda a história da educação pública ou a história da educação privada, faz-se presente o outro polo. Por essas assertivas, afirma-se que esses polos se originaram na época moderna, dela decorrente sua especificidade conceitual. Saviani (2005) elucida que este fenômeno liga-se ao advento do modo capitalista de produção, característico da modernidade, o qual introduziu, pela via do "fetichismo da mercadoria, a opacidade nas relações sociais" (id., 2005, p. 168). É importante destacar que a estruturação da educação pública brasileira se deu no auge da consolidação do capitalismo como modo de produção, contando com a crescente participação da iniciativa privada, especialmente a empresarial, na composição econômica, política e social do país.

A passagem do século XIX para o século XX, no Brasil, foi marcada pelo avanço do "capitalismo, com a consequente industrialização e urbanização do país, com a formação de uma classe média, tudo sob a impregnação do liberalismo políticoeconômico" (SEVERINO, 2005, p. 32). Nesse contexto, a relação contraditória entre 


\section{HEM entoarga}

ISSN: 1984-6444 | http://dx.doi.org/10.5902/1984644433097

os interesses públicos e privados em torno de questões econômicas, políticas, sociais e educacionais permitiu a alteração novamente do sentido da categoria público e privado, ou seja, "a minimização do Estado na condução das políticas sociais, que ficam dependentes apenas das leis do mercado, tido como dinâmica própria da esfera do privado" (id., 2005, p. 33-34). Assim, fortaleceu-se a concepção de que o Estado não representa diretamente o interesse público, sendo um espaço de contraposição de interesse público e privado. Trata-se, no Brasil, de uma instituição que, "apesar de estatal, não é efetivamente pública, é autenticamente privada, apesar de custeada com o sangue e o suor do trabalho realizado pelo conjunto da sociedade civil" (SEVERINO, 2005, p. 36-37).

Os trabalhos de Adrião et al (2009, p. 799), apresentam a hipótese de que há um incremento da dependência das esferas municipais públicas junto aos setores privados diante das ampliações das responsabilidades dos municípios, com a oferta e manutenção da educação básica, sem ter ocorrido uma estruturação adequada do ensino, no aspecto técnico-político, pedagógico e da gestão local, com participação do governo federal.

Para Robertson e Verger (2012), no setor educacional, cuja atividade política e social é complexa, além de relacionada com o setor de serviço dos interesses públicos, o processo de parceria com o setor privado tem se expandido rapidamente pelos países capitalistas (ROBERTSON; VERGER, 2012, p. 1.134). Segundo esses autores, o processo de parceria com o setor privado é uma nova face de uma antiga agenda de privatização que faz parte de uma indústria em um ramo empresarial em rápido crescimento. São formas de privatização da educação que estão modificando as políticas educacionais e de financiamento, apresentando possível solução para resolver os profundos problemas sistêmicos dos sistemas de ensino, tais como o acesso à escola, à qualidade e à equidade (id., 2012, p. 1.135).

No que tange ao processo de parceria com o setor privado, manifestam-se como uma forma diversificada de aplicação de recursos públicos na educação, de forma privatizante (WHITTY; POWER, 2002, p. 16). É preciso, não obstante, examinar 


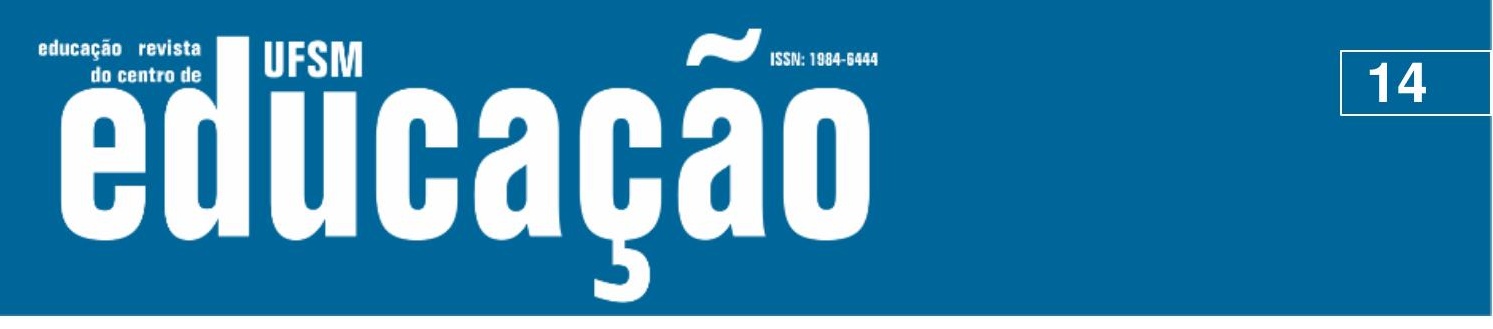

ISSN: 1984-6444 | http://dx.doi.org/10.5902/1984644433097

se tem ocorrido uma privatização da educação em uma escala expressiva a partir desses processos. Nesse sentido, Whitty e Power (2002) alegam que

[...] na maioria dos casos, mercantilização é, provavelmente, a melhor metáfora para o que tem acontecido ou, para ser ainda mais preciso, o desenvolvimento de quase-mercados nos serviços do Estado-Nação e ou do Estado-Providência. Muitos críticos veem estes quase-mercados educativos como envolvendo a combinação da escolha parental e a autonomia da escola, juntamente com um maior grau de regulação pública financeira e governamental. Este tipo de reforma tem sido evidente em muitos sistemas de educação pública de massas (WHITTY; POWER, 2002, p. 16).

Deste modo, tem se organizado um quase-mercado para a educação. De acordo com Whitty e Power (2002, p. 16), os quase-mercados são regulamentados por meio de sistemas de avaliação, fiscalização e financiamento governamental. $O$ que distingue um quase-mercado é a separação entre comprador (Estado), fornecedor (escolas) e usuários (pais e alunos), com a possibilidade de escolha por parte destes últimos. Nesse sentido, alguns aspectos da mercantilização da educação contribuem para a privatização, num sentido ideológico e não estritamente econômico e

[...] isto inclui fomentar a crença de que a abordagem do sector privado é superior à que é tradicionalmente adaptada no sector público; forçar as instituições do sector público a operar mais como as do sector privado; e encorajar a tomada de decisão privada (individual/familiar) em detrimento do processo burocrático (WHITTY; POWER, 2002, p. 17).

Em tal contexto, "a educação surge definida mais como um bem privado do que uma questão pública, transformando-se a tomada de decisão educativa numa questão de escolha do consumidor em vez de direitos dos cidadãos" (WHITTY; POWER, 2002, p. 17). Contudo, os defensores dos quase-mercados em educação argumentam a favor de maior diversidade de financiamento sucedido desse processo. Porém, segundo esses autores, a crítica tem mostrado o contrário, que os "quase-mercados tem possibilitado aumentar a desigualdade entre as escolas" (id., 2002, p. 17).

Assim, Robertson e Verger (2012) advertem que as parcerias surgem articuladas a mudanças mais amplas nas concepções ideológicas e conceituais estabelecidas nas políticas dos governos que se deram em direção a uma terceira via entre o Estado e o mercado, como "um corretivo para a presença demasiada do 


\section{THEM entoarga}

ISSN: 1984-6444 | http://dx.doi.org/10.5902/1984644433097

Estado (keynesianismo), por um lado, e a ausência dele, por outro (privatização)", tornando-se uma ligação entre cada setor e capitalizando os valores de cada parceiro (id., 2012, p. 1.139). Para esses autores, o aparecimento de um discurso global de defesa sobre o processo de parceria com o setor privado tem sido relevante em torno dos temas da educação para o desenvolvimento.

Nota-se que a presença do privado no público apresenta certa sofisticação dos discursos pedagógicos, por meio de premissas oriundas do âmbito empresarial, delineando novos horizontes para o trabalho da docência, como uma prática organizativa que, na Secretaria Municipal de Manaus, efetiva-se no trabalho dos professores em estágio probatório da educação infantil e dos anos iniciais do ensino fundamental. Inicialmente, esta experiência formativa se insere em forma de projeto piloto e envolve os professores de educação infantil e de anos iniciais do ensino fundamental da rede municipal de ensino de Manaus.

Com isso, tem ocorrido a materialização de altos investimentos de recursos públicos pagos pela administração pública por serviços privados que poderiam ser desempenhados na própria esfera pública. Já que esta Secretaria Municipal de Educação tem em sua estrutura organizacional a Divisão de Desenvolvimento Profissional do Magistério (DDPM), que desenvolve o programa de formação continuada denominada Tapiri, que atende anualmente os profissionais da educação, em três turnos, que recebem formação continuada presencial, semipresencial e à distância, a técnicos pedagógicos e administrativos, além de diretores, nas etapas da educação básica do município de Manaus. (MANAUS, 2014, p.4)

Desse modo, pode-se argumentar que tem ocorrido um fetichismo do Programa de Tutoria Educacional (PTE), pois houve uma valorização acentuada da sua metodologia, ou seja, do seu produto e serviço resultantes desse convênio com a SEMED em Manaus, em que um processo que é social, passa a ser visto de forma naturalizada e independente das relações humanas (MARX, 2008).

Marx (1983, p. 71 apud DUARTE, 2012 p.9) esclarece que o fetichismo surge exatamente quando uma determinada relação social entre os próprios homens assume para eles "a forma fantasmagórica de uma relação entre coisas [...] os 


\section{HEM etituará}

ISSN: 1984-6444 | http://dx.doi.org/10.5902/1984644433097

produtos do cérebro humano parecem dotados de vida própria, figuras autônomas, que mantêm relações entre si e com os homens" (DUARTE, 2012 p.9). Marx, ainda complementa: "assim, no mundo das mercadorias, acontece com os produtos da mão humana. Isso eu chamo o fetichismo que adere aos produtos de trabalho, tão logo são produzidos como mercadorias" (id., 2012, p.10).

Portanto, ao se implantar o Programa de Tutoria Educacional (PTE) da Fundação Itaú Social (FIS), conforme o termo de convênio de no 12 de 2015, entre a SEMED e a Fundação Itaú Social, na forma do Plano de Trabalho, que define estratégias e análises à implementação de soluções educacionais para o enfrentamento das questões relativas à educação infantil e ao ensino fundamental na rede pública municipal de ensino. Esta Secretaria tem divulgado para os profissionais da educação infantil e ensino fundamental a crença de que esse produto e serviço adquirido, são resultados da ação humana e estão incorporados nos produtos e serviços em alguns estados brasileiros, são capazes de promover, por si só, transformações substanciais na vida das crianças e jovens do município de Manaus, elevando a qualidade da educação.

Analisando a ampliação do Programa Tutoria na Homepage institucional da Fundação Itaú Social (FIS), foi constatado que, durante o ano de 2015, tinha sua abrangência nas secretarias de educação dos Estados do Amazonas, Ceará, Goiás, São Paulo e Rio Grande do Sul. Já no ano de 2016, houve significativo crescimento das secretarias nos estados de Rondônia, Mato Grosso, Mato Grosso do Sul e Tocantins. Neste contexto, apresenta-se o material Guia de Tutoria, disponibilizado pela Fundação Itaú Social (FIS), que explica sobre a customização - consta que o tutor treina o seu olhar para reconhecer os pontos fortes, as áreas de desenvolvimento e o estilo de aprendizagem de seu tutorado (professor). Portanto, diante do exposto, este material da FIS, não poderia deixar de ser uma forma de instrumentalizar esses professores. O material analisado incorpora os preceitos neoliberais, oferecendo ao professor um novo status como tutorado. 


\section{DFM Gutrahâ}

ISSN: 1984-6444 | http://dx.doi.org/10.5902/1984644433097

\section{Conclusões}

Este trabalho procurou desvelar a materialidade do PROEMEM na rede pública municipal de ensino de Manaus, evidenciando a lógica do mercado educacional no contexto da parceria com o setor privado para a formação continuada de professores nas etapas da educação básica do ensino público municipal.

Tomou-se, como método de análise, o materialismo dialético, tendo em vista que esse método permitiu analisar o particular, nesse caso o PROEMEM, implantado na Secretaria Municipal de Educação (SEMED) de Manaus, em seu movimento dialético com o universal que se refere ao mercado educacional, em seu estágio de privatização da educação.

Entende-se que público e privado se expressam como polos opostos e se revelam nas contradições que emergem nos espaços das lutas de classes, por meio dos sujeitos histórico-sociais em movimentos concretos. Nessa direção, considera-se que a denominada parceria com o setor privado no campo educacional oculta interesses hegemônicos do grande capital, de forma disfarçada e camuflada, para legitimar seus projetos, que seguem a ideologia da política neoliberal. Assim, a transferência da responsabilidade da educação básica pública para a ampliação da presença direta do setor privado na definição das políticas educativas se configura e materializa sobre as dimensões da privatização da educação básica no Brasil, pois se trata de uma relação conflitante e antagônica, em confronto constante com as necessidades de reprodução do capital e com as múltiplas necessidades humanas.

Nesse contexto, em Manaus, há um volume crescente de contratos, convênios e acertos entre a SEMED e os setores privados. Como exemplo, o procedimento de formação em serviço de professores em estágio probatório da educação infantil e dos anos iniciais do ensino fundamental, realizado pelo Programa Tutoria Educacional, da Fundação Itaú Social (FIS); o Programa de Correção de Fluxo, como o Se Liga, para alunos não alfabetizados, e o Acelera Brasil, para alunos alfabetizados, por meio da parceria firmada com o Instituto Ayrton Senna (IAS), em vigência nas escolas de Manaus. 


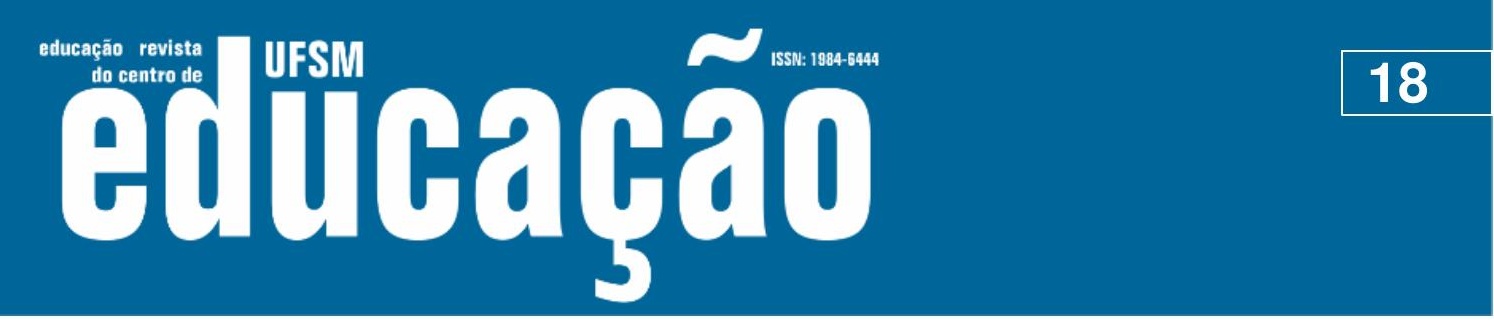

ISSN: 1984-6444 | http://dx.doi.org/10.5902/1984644433097

Segundo, verifica-se que, na educação municipal de Manaus, tem se concretizado um intricado processo de privatização que compõe as faces públicas e privadas na educação infantil e no ensino fundamental. Nessas etapas de escolarização analisadas, a política educacional mantém-se orientada pela lógica do Banco Interamericano de Desenvolvimento (BID), perante o grande objetivo atual das forças do capital que, em âmbito mundial, anseiam consagrar a pequena política e a pseudo-ética do privatismo desenfreado como elementos fundamentais de um senso comum que sirva de base à sua hegemonia. Além disso, é importante entender os pressupostos e os fundamentos que norteiam as alianças entre interesses públicos e privados no cenário educacional no sentido de esclarecer seus pretextos e a sua natureza. Considera-se que uma sociedade fundamentada na democracia deve garantir o debate crítico e a proposição de ideias e alternativas para que as relações mercantis orientadas pela lógica do mercado não imperem de forma dominante e nem se estabeleçam de forma encantadora e singular.

\section{Referências}

ADRIÃO, Theresa. et al. Uma modalidade peculiar de privatização da educação pública: a aquisição de "sistemas de ensino" por municípios paulistas. Educação \& Sociedade, Campinas, SP, vol. 30, n. 108, p. 799-818, out. 2009.

BRASIL. Decreto no 6.094, de 24 de abril de 2007. Dispõe sobre a implementação do Plano de Metas Compromisso Todos pela Educação. Brasília, DF: Senado, 2007. Disponível em: http://www.planalto.gov.br/ccivil_03/_ato20072010/2007/decreto/d6094.htm Acesso em: 25 abr. 2017.

BRASIL. Diário Oficial [da] República Federativa do Brasil, Poder Executivo, Brasília, DF, n. 95, 19 maio 2017. Disponível em: https://www.jusbrasil.com.br/diarios/147090309/dou-secao-1-19-05-2017-pg-2.

Acesso em: 13 jul. 2017

DUARTE, Newton. A rendição pós-moderna à individualidade alienada e a perspectiva marxista da individualidade livre e universal. In: DUARTE, Newton (Org.). Crítica ao fetichismo da individualidade. 2. Ed. Campinas: Autores Associados, 2012. p. 197217./

FUNDAÇÃO ITAÚ SOCIAL. Gestão educacional: ciclo de debates 2012. São Paulo: Fundação Itaú Social, 2013. Disponível em: http://www.fundacaoitausocial.org.br.html Acesso em: 29 abr. 2016. 


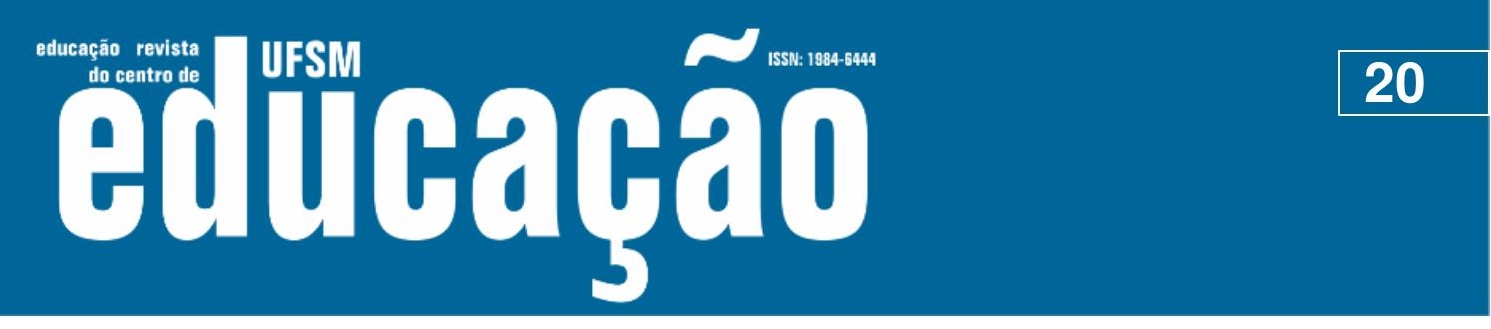

ISSN: 1984-6444 | http://dx.doi.org/10.5902/1984644433097

ROBERTSON, Susan; VERGER, Antoni. A origem das parcerias público-privada na governança global da educação. Educação e Sociedade, Campinas, SP., v. 33, n. 121, p. 1133-1156, out.-dez. 2012. Disponível em http://www.cedes.unicamp.br Acesso em: 12 jan. 2016.

SARTI, Flávia Medeiros. O triângulo da formação docente: seus jogadores e configurações. Educação e Pesquisa, São Paulo, v. 38, n. 2, p. 323-338, abr./jun. 2012.

Disponível

em:

http://www.periodicos.rc.biblioteca.unesp.br/index.php/educacao/article/view/10286

Acesso em: 07 jan. 2017.

SARTI, Flávia Medeiros. Dos limites e das possibilidades da universitarização do magistério: os professores e o consumo de produtos acadêmicos. In: SOUZA, Denise Trento Rebello de; SARTI, Flavia Medeiros (Orgs). Mercado de formação docente: constituição, funcionamento e dispositivos. Belo Horizonte: Fino Traço, 2014. p. 129-149.

SAVIANI, Dermeval. O público e o privado na história da educação brasileira. In: LOMBARDI, José Claudinei; JACOMELI, Mara R. M.; SILVA, Tânia M. T. da (Orgs.). O público e o privado na história da educação brasileira. Campinas: Autores Associados, UNISAL, 2005.p. 167-176.

SEVERINO, Antônio Joaquim. O público e o privado como categoria de análise em educação. In: LOMBARDI, José Claudinei; JACOMELI, Mara R. M.; SILVA, Tânia M. T. da. O público e o privado na história da educação brasileira. Campinas: Autores Associados, UNISAL, 2005.p. 31-40.

VIDIGAL, Carlos Eduardo. A nova ordem mundial. In: OLIVEIRA, Henrique Altemani; LESSA, Antônio Carlos (Org.) Política internacional contemporânea: mundo em transformação. São Paulo: Saraiva, 2011 p.1-16

WHITTY, Geoff; POWER, Sally. A escola, o Estado e o mercado: a investigação do campo actualizada. Currículo sem Fronteiras, v.2, n.1, pp.15-40, Jan/Jun 2002. Disponível em: www.curriculosemfronteiras.org. Acesso em agosto de 2016.

\section{Correspondência}

Rudervania da Silva Lima Aranha - Universidade Federal do Amazonas - Av. General Rodrigo Octavio Jordão Ramos, n.1200 - Coroado I - CEP 69067-005. Manaus, Amazonas, Brasil.

\section{(C) $(1) \Theta$}

This work is licensed under a Creative Commons Attribution-NonCommercial 4.0 International (CC BY-NC 4.0) 